\title{
Algorithms for dairy barn design: Maternity and milking areas
}

\author{
M. E. Fernández, ${ }^{1}$ R. A. Mariño, and X. C. Carreira \\ Department of Agroforestry Engineering, University of Santiago de Compostela, 27002 Lugo, Spain
}

\begin{abstract}
This paper presents a series of algorithms for dairy barn design. The aim of the study was to develop algorithms for the design of new barn areas that can added to the main barn areas (resting, feeding, and exercise) to complement barn layout. More specifically, we developed design and dimensioning schemes to incorporate the maternity area and the milking area (holding pen and milking parlor) into dairy barns. Each algorithm requires input design parameters related to the characteristics of the areas considered. The output of the algorithms provides layout solutions for the maternity and milking areas and the overall dimensions of both areas, which enables the user to assess the possibility of incorporating maternity and milking into a dairy barn composed of resting, exercise, and feeding areas. The algorithms presented in this paper allow for space optimization by using the values defined for the design parameters considered.
\end{abstract}

Key words: freestall barn, design, maternity, milking

\section{INTRODUCTION}

Many factors must be considered when designing free-stall housing for dairy cattle. The characteristics of the elements for the internal distribution of the barn must ensure cow welfare, a key goal in the design of dairy barns. Moreover, the arrangement of internal distribution elements must ensure easy herd management and must facilitate the performance of the tasks related to cattle care and milk production. These criteria must be considered as goals when designing the layout of a free-stall barn. Furthermore, the optimization of the space adjacent to the building area is an intrinsic goal of layout design.

The dimensions of the elements of internal distribution are the first parameters required for barn design. Such dimensions are particularly related to comfortable housing and to the level of cow welfare attained. Cow

Received July 21, 2008.

Accepted December 16, 2008.

${ }^{1}$ Corresponding author: melena.fernandez@usc.es welfare is at high level when cows can behave naturally in the barn (Wechsler, 2007). Cow welfare is also related to management issues that are often connected to the characteristics of the barn. Management plays a key role in calving or milking areas (Sanftleben et al., 2007).

Resting area, exercise area, and feeding area are essential parts of a free-stall barn. The dimensions of the distribution elements of these parts play an important role in ensuring that cows can behave naturally; for example, when they are resting in the stall, when they stand up, or when they lie down. The influence of these factors on cow behavior is known (Haley et al., 2000; Tucker et al., 2004; Veissier et al., 2004). Likewise, the dimensions of the alleys and the dimensions of feed elements such as the feed bunk space per cow or the number of stalls can affect cow behavior (DeVries et al., 2004; Huzzey et al., 2005; DeVries and von Keyserlingk, 2006).

The first step in the design process is to determine the dimensions of such elements. The values selected at this stage affect barn layout and may produce different solutions. In addition, the most common barn arrangements, 2-row barns with head-to-head stalls, 2-row barns with head-to-wall stalls, and 3-row barns, produce different layout solutions (Carreira Pérez, 1996; Bickert et al., 2000; BTPL, 2005). In a previous article, we defined a series of algorithms that enabled the generation of distributional solutions for barns considering the 3 main areas of a barn (resting, exercise, and feeding) and all the parameters related to the elements of internal distribution (Fernández et al., 2006).

The dimensions and arrangement of the internal distribution elements and the number of stalls determine the length required for the resting and feeding areas. The number of stalls is related to stocking density at a given moment while cows are resting or feeding. Because stocking density affects cow behavior at the feed bunks (Huzzey et al., 2006; Mentink and Cook, 2006; ValLaillet et al., 2008) or at the resting area (Cooper et al., 2007; Fregonesi et al., 2007; Krawczel et al., 2008), such effects must be taken into consideration and assessed when selecting a value for this parameter.

For a barn with stalls arranged in rows and a 1:1 stall-to-cow ratio while feeding and resting, the length 
of the resting area is shorter than the length of the feeding area (except for the single-row tail-to-tail arrangement). To optimize space use in the barn, such a difference in length can be used to incorporate other areas that are necessary for herd management, such as maternity and milking areas. Moreover, by optimizing space use, the structural solution used for the building can be optimized (Fernández et al., 2008).

The maternity area is the area where calving cows are housed. Maternity areas are important for herd management, and the characteristics of such areas must be taken into consideration when designing a barn. The time during which cows are held in the maternity area can vary depending on the management system of each farm. Generally, cows are moved to the maternity area some time before expected calving. One of the tenets of good calving management includes moving cows to the maternity unit on time (Mee, 2004). Factors concerning herd management during the dry period before calving may affect some aspects related to milk production; for example, bedding material may affect somatic cell counts in early lactation (Green et al., 2007, 2008). After calving, cows may be held in the calving area for some time before returning to the dairy herd.

The characteristics of the milking area, such as the dimensions of the area or the organization of milking clusters, affect ease of management and cow welfare during milking. Appropriate design is important to both the cows and the farmer (Maller et al., 2005) and is related to milking efficiency, which is one of the parameters used to assess milking systems (Wagner et al., 2001). The design of the milking area is an important phase in the overall design of a new barn or when remodeling the existing facilities (Smith et al., 1997).

The research presented in this paper builds on previous research on the development of algorithms for layout design of free-stall barns for dairy cattle (Fernández et al., 2006). The overall objective of the research was to develop several algorithms to assist farmers and decision-makers during the design process. The specific aim of this paper was to develop algorithms for the design of the maternity area (also termed calving area) and the milking area by using input parameters related to the elements of internal distribution. Such algorithms were used to assess the possibility of incorporating the maternity and milking areas into the space adjacent to the resting area, and were defined such that they can be used as a basis for the development of a software application that facilitates the use of the algorithms.

\section{MATERIALS AND METHODS}

The method comprised 2 stages: 1) determination of the general characteristics of the maternity and milk- ing areas and definition of criteria for the design and arrangement of both areas, and 2) development of algorithms and assessment of the possibility of incorporating maternity and milking in the space adjacent to the resting area, obtained from the design of the barn layout. The development of the algorithms was performed such that the final algorithms could be implemented within a software application.

The availability of a well-equipped maternity area allows the farmer to take the appropriate measures at this stage. One of the characteristics that favor herd management during calving is the size of individual maternity pens; recommended values range from 3 to $4 \mathrm{~m}$ (Carreira Pérez, 1996; Bickert et al., 2000; Anonymous, 2001). The position of the calving area within the barn is another important characteristic insofar as it should facilitate the monitoring of calving cows (Bickert et al., 2000) and allow for proximity between calving cows and their herd (BTPL, 2005). Such characteristics affect the layout of the barn and the final dimensions of the calving area.

The characteristics of the 2 main components of the milking area, the holding pen and the milking parlor, were considered in the development of the algorithms. To minimize cow stress during the milking routine, the design of these areas must not disturb cow entrance (Hillerton et al., 2002) or side choice (Grasso et al., 2007). Cows should not spend more than $1 \mathrm{~h}$ in the holding pen during each milking (Bickert et al., 2000), and the holding pen should provide 1.25 to $1.50 \mathrm{~m}^{2}$ / cow (Carreira Pérez, 1996; Bickert et al., 2000; BTPL, 2005). Consequently, the total area of the holding pen is dependent on the size of the milking herd, which in turn is dependent on milking time and on the size of the milking parlor. Accordingly, the characteristics of the milking system of each farm and the characteristics of the milking parlor must be considered to define the final dimensions of the holding pen.

Because the size of the milking parlor is dependent on the duration of the milking routines and on the number of workers (Carreira Pérez, 1996; Burks et al., 2006), the optimum number of clusters per person must be defined according to the specific milking conditions on each farm (Hansen, 1999). The use of appropriate milking routines is one of the factors that affect milk flow traits in dairy cows (Sandrucci et al., 2007). The type of milking parlor affects the final dimensions of the parlor because of the variable position of cows with respect to the milker pit (forming an angle, parallel, or perpendicular).

The most significant aspects of the development of algorithms for the design of the maternity and milking areas are presented in the sections below. In both cases, the available space adjacent to the resting area, 


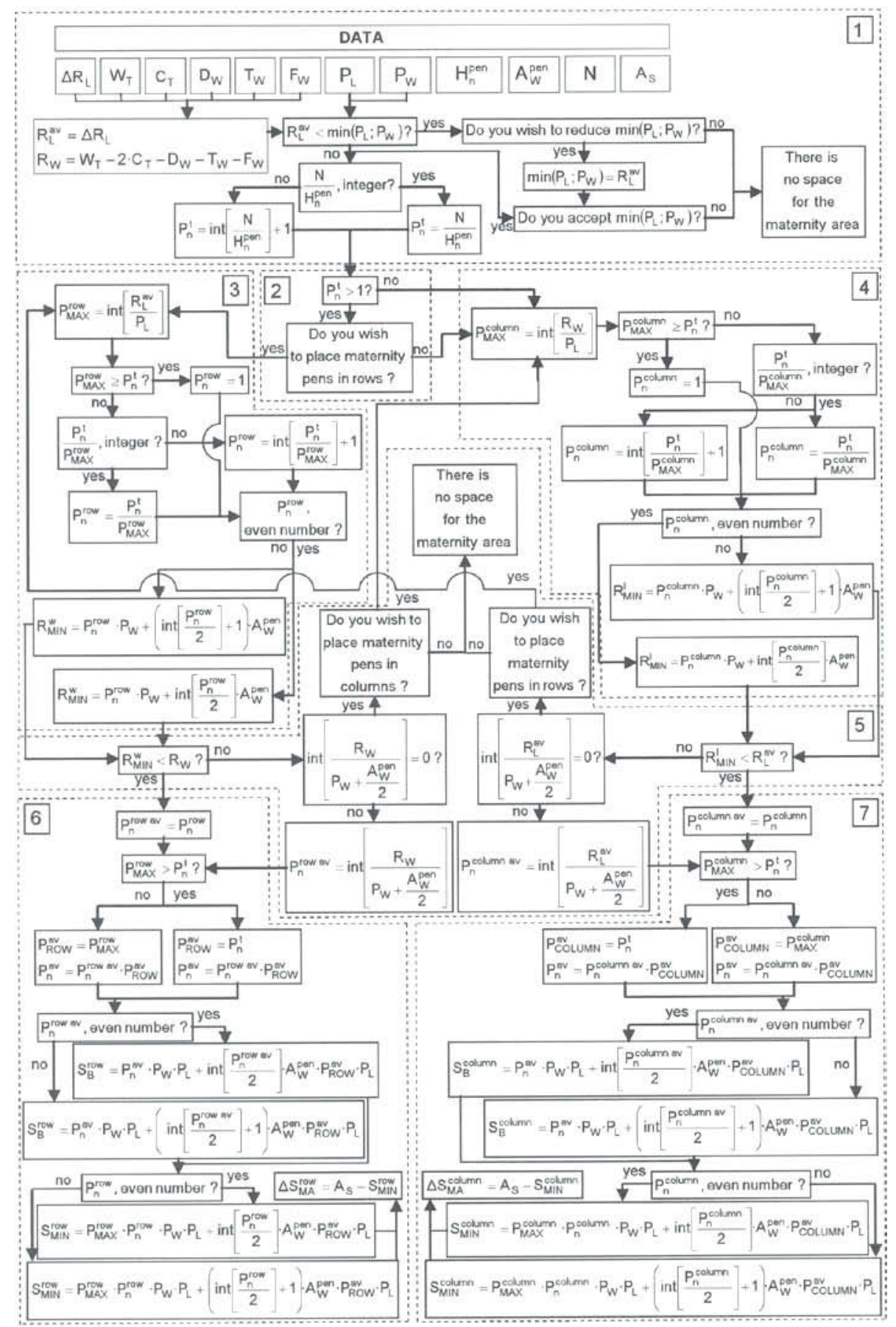

Figure 1. Algorithm for the design of the calving area: $A_{S}=$ additional space for other areas (e.g., maternity or calving area); $A^{\text {pen }}{ }_{W}=$ service alley width (between rows or columns of pens); $\mathrm{C}_{\mathrm{T}}=$ column thickness; $\mathrm{D}_{\mathrm{W}}=$ driveway width; $\mathrm{F}_{\mathrm{W}}=$ feed alley width; $\mathrm{H}_{\mathrm{n}}$ pen $=$ number of cows per maternity pen; $\mathrm{N}=$ herd size; $\mathrm{P}_{\mathrm{COLUMN}}{ }^{\text {av }}=$ available number of pens per row; $\mathrm{P}_{\mathrm{L}}=$ maternity pen length; $\mathrm{P}_{\mathrm{MAX}}{ }^{\text {column }}=$ maximum number of maternity pens in each column; $\mathrm{P}_{\mathrm{MAX}}{ }^{\text {row }}=$ maximum number of maternity pens in each row; $\mathrm{P}_{\mathrm{n}}{ }^{\text {av }}=$ available number of maternity pens; $\mathrm{P}_{\mathrm{n}}$ column $=$ number of columns of maternity pens required; $\mathrm{P}_{\mathrm{n}}{ }^{\text {column av }}=$ available number of columns of maternity pens; $\mathrm{P}_{n}{ }^{\text {row }}=$ number of rows of maternity pens required; $\mathrm{P}_{\mathrm{n}}{ }^{\text {row av }}=$ available number of rows of maternity pens; $\mathrm{P}_{\mathrm{n}}{ }^{t}=$ total number of maternity pens; $\mathrm{P}_{\text {Row }}{ }^{\text {av }}=$ available number of pens per row; $\mathrm{P}_{\mathrm{W}}=$ maternity pen width; $\mathrm{R}_{\mathrm{L}}{ }^{\text {av }}=$ available length in the resting area to place maternity pens; $\mathrm{R}_{\mathrm{MIN}}{ }^{1}=$ minimum length required in the resting area; $\mathrm{R}_{\mathrm{MIN}}{ }^{\mathrm{w}}=$ minimum width required in the resting area; $\mathrm{R}_{\mathrm{W}}=$ resting area width (including free stall alley width); $\mathrm{S}_{\mathrm{B}}{ }^{\text {column }}$ $=$ building area in the maternity for pens arranged in columns; $\mathrm{S}_{\mathrm{B}}{ }^{\text {row }}=$ building area in the maternity for pens arranged in rows; $\mathrm{S}_{\mathrm{MIN}}{ }^{\text {clumn }}=$ minimum area needed to place the number of columns of maternity pens required; $\mathrm{S}_{\mathrm{MIN}}{ }^{\text {row }}=$ minimum area needed to place the number of rows of maternity pens required; $\mathrm{T}_{\mathrm{W}}=$ feeding table width; $\mathrm{W}_{\mathrm{T}}=$ total outside barn width; $\Delta \mathrm{S}_{\mathrm{MA}}{ }^{\text {column }}=$ increase in the area needed in the maternity with respect to the building area for maternity pens arranged in columns; $\Delta \mathrm{S}_{\mathrm{MA}}{ }^{\text {row }}=$ increase in the area needed in the maternity with respect to the building area for maternity pens arranged in rows; $\Delta \mathrm{R}_{\mathrm{L}}=$ increase in resting area length. 
which results from the greater length of the feeding area compared with the resting area, has been previously calculated by using the algorithms developed for barn layout design (Fernández et al., 2006). The area of the space adjacent to the resting area is an output of the algorithms.

\section{Maternity Area}

The characteristics of the maternity area that can affect barn layout are the following: number of individual pens (depending on herd size), pen dimensions, and arrangement of pens once the number of pens has been determined. These characteristics correspond to the parameters used to develop the algorithms. The number of cows associated with each individual pen and the dimensions of pens have been considered as inputs that must be defined by the user in the design process. With regard to the arrangement of pens, 2 options were considered: pen rows aligned parallel to the longitudinal axis of the barn (hereafter termed "rows"), with service alleys between rows; and pen rows aligned perpendicular to the longitudinal axis of the barn (hereafter termed "columns"), with service alleys between rows.

When pens are arranged in parallel rows (i.e., rows), the largest dimension (length) of the pen is aligned parallel to the longitudinal axis of the barn. When pens are arranged in perpendicular rows (i.e., columns), the smallest dimension (width) of the pen is aligned parallel to the longitudinal axis of the barn.

The algorithm enables the user to obtain the number of pens that can be incorporated into the space adjacent to the resting area based on the input values for the design parameters used. In addition, the user can evaluate the layout of the maternity by assessing space requirements in the area, which optimizes the use of the available space.

\section{Milking Area}

The algorithms designed to determine the dimensions of the milking area calculate the area required for the holding pen, the number of milking points needed in the milking parlor, and milking efficiency. The algorithm takes into account the milking routine used and the preferences of the user in terms of the organization of milking operations (such as milking time or number of milkers). By applying the algorithm, the area needed for the milking area could be defined and the possibility of placing the milking area in the space adjacent to the resting area could be assessed.

\section{RESULTS AND DISCUSSION}

Figure 1 shows the algorithm developed for the design of the calving area. In this algorithm, the dimensions of the space adjacent to the resting area are used as input data. First, the number of calving pens needed in the maternity area is determined as a function of the total number of cows and the number of cows per maternity pen. Then, the arrangement of the maternity area (rows or columns) is chosen and the dimensions of the maternity are calculated based on the length, width, and number of pens. After that, the algorithm determines whether the whole maternity can be placed in the space adjacent to the resting area. If so, the algorithm produces the results for the selected arrangement. Otherwise, the algorithm allows the user to change the arrangement or to adjust the maternity to the available space. In the paragraphs below, we describe the algorithm in more detail.

Once the available length (the difference in length required between feeding area and resting area) is known and the size of the calving pen is determined, the number of pens that can be incorporated in the space available is determined based on the number of cows per pen (section 1 of Figure 1). The dimensions (length and width) of calving pens are considered as input data. The design algorithm allows the user to change input values if these values do not conform to the space available. If necessary, pen size can be adjusted to the available space. If the user does not want to change pen size, the algorithm reports that there is not enough space available to incorporate the calving area inside the barn. Finally, the number of calving pens needed is calculated according to the ratio of number of cows to number of cows associated to each pen.

In section 2 of Figure 1, the arrangement of calving pens (in rows or in columns) is defined. After that, sections 3 and 4 of the algorithm determine the distribution of the calving area (number of rows, columns, and service alleys) and the minimum size required to incorporate the maternity area in the space adjacent to the resting area.

When only one calving pen is required, the pen is placed according to the arrangement in columns, with the shorter side of the pen (width) aligned parallel to the feed alley. The arrangement in columns is chosen because it requires the shortest length in the calving area.

The design with pens arranged in rows is developed in section 3 of Figure 1, and the design with pens arranged in columns is developed in section 4 of the algorithm. For the design with pens arranged in rows, 
the algorithm takes the length of the space adjacent to the resting area as a reference and determines the minimum width required to incorporate the maternity area. The maximum number of pens that can be included in a row is determined based on pen length and on the length of the space adjacent to the resting area. This information allows the user to determine the number of rows required to incorporate all the pens. Finally, the minimum width of the space adjacent to the resting area that is required to incorporate the calving pens is calculated. The value obtained for minimum width includes all the rows and service alleys between rows.

The design with pens arranged in columns (section 4) is rather similar to the design described above. In this case, the algorithm takes the width of the space adjacent to the resting area as a reference and calculates the minimum length required to include the maternity in this space. The number of pens that can be included in a column is determined based on pen width and on the width of the space adjacent to the resting area. This information allows the user to determine the number of columns required to incorporate all the pens. Finally, the algorithm calculates the minimum length of the space adjacent to the resting area required for the incorporation of the calving area in that space. The value obtained for minimum length includes all the calving pen columns and all the service alleys between columns.

Section 5 of the algorithm compares the minimum dimensions (length and width) required for the space adjacent to the resting area to the actual dimensions of the space. By comparing both values, the algorithm can determine whether the maternity area can be placed in the space adjacent to the resting area according to the arrangement (in rows or in columns) and dimensions chosen. If the dimensions required for the maternity area are larger than the actual dimensions, the algorithm produces 2 solutions. The first solution is changing the arrangement considered. To change the arrangement considered, the algorithm includes a loop that allows the user to modify the arrangement of pens. The second solution is calculating the number of rows or columns that would actually fit in the space available to reorganize the calving area.

Once the number of pens and rows that must be included in the calving area has been determined, the algorithm allows the user to calculate the building area for the maternity (section 6). In addition, the algorithm assesses the design output in terms of surface area by analyzing the level of use of the area that was initially available for the maternity. More specifically, the algorithm calculates the area left after having placed the maternity area in the space adjacent to the resting area.
The same procedure is used for pens arranged in columns (section 7). The algorithm determines the area occupied by the calving area and the level of use attained for the surface area initially available.

For the milking area, 2 algorithms were developed: one for the design of the holding pen and the other for the design of the milking parlor.

Figure 2 shows the algorithm developed for the design of the holding pen. The algorithm is organized into 3 sections. The aim of section 1 is to obtain the number of cows that can be housed in the holding pen according to the space adjacent to the resting area and on the area per cow in the resting area. Section 2 calculates the number of groups into which the herd must be divided so that every cow can walk through the holding pen; it also determines the size of each group. Finally, section 3 calculates the final area required for the holding pen based on the number of cows per milking group and the area left for the milking parlor based on the area initially available.

Because the algorithm developed for the design of the milking area is very long (Figure 3), this algorithm is shown in the 4 subparts (panels) following the complete algorithm (panels 3.1, 3.2, 3.3, and 3.4). The development of the algorithm for the design of the milking parlor was based on 3 essential parameters: number of milking points, number of operators, and overall work time. Two of the most important variables that affect such parameters are milk removal time and milking routine time. At the start of the algorithm, a series of input data including milk removal time and milking routine time are defined. First, the algorithm calculates minimum milking time by dividing the product of modified milking routine time and the number of cows by the number of operators (panel 3.1 in Figure 3). Moreover, total milking time is calculated as the difference between overall work time and the time devoted to other tasks; for example, preparing the parlor. If total milking time exceeds minimum milking time, milking can be organized according to the input data and the algorithm continues in panel 3.1 of Figure 3. If total milking time is shorter than minimum milking time, the input data must be modified and the algorithm continues in panel 3.2 of Figure 3, where the user has the option to increase the number of operators. If the user does not want to increase the number of operators, the algorithm jumps to panel 3.3 of Figure 3, which gives the option of increasing total milking time. If, after such an increase, total milking time is still shorter than minimum milking time, the algorithm goes to panel 3.4 of Figure 3, which again gives the option of increasing the number of operators.

In each of these parts (panels 3.1 to 3.4 of Figure 3), the algorithm estimates the number of milking points 


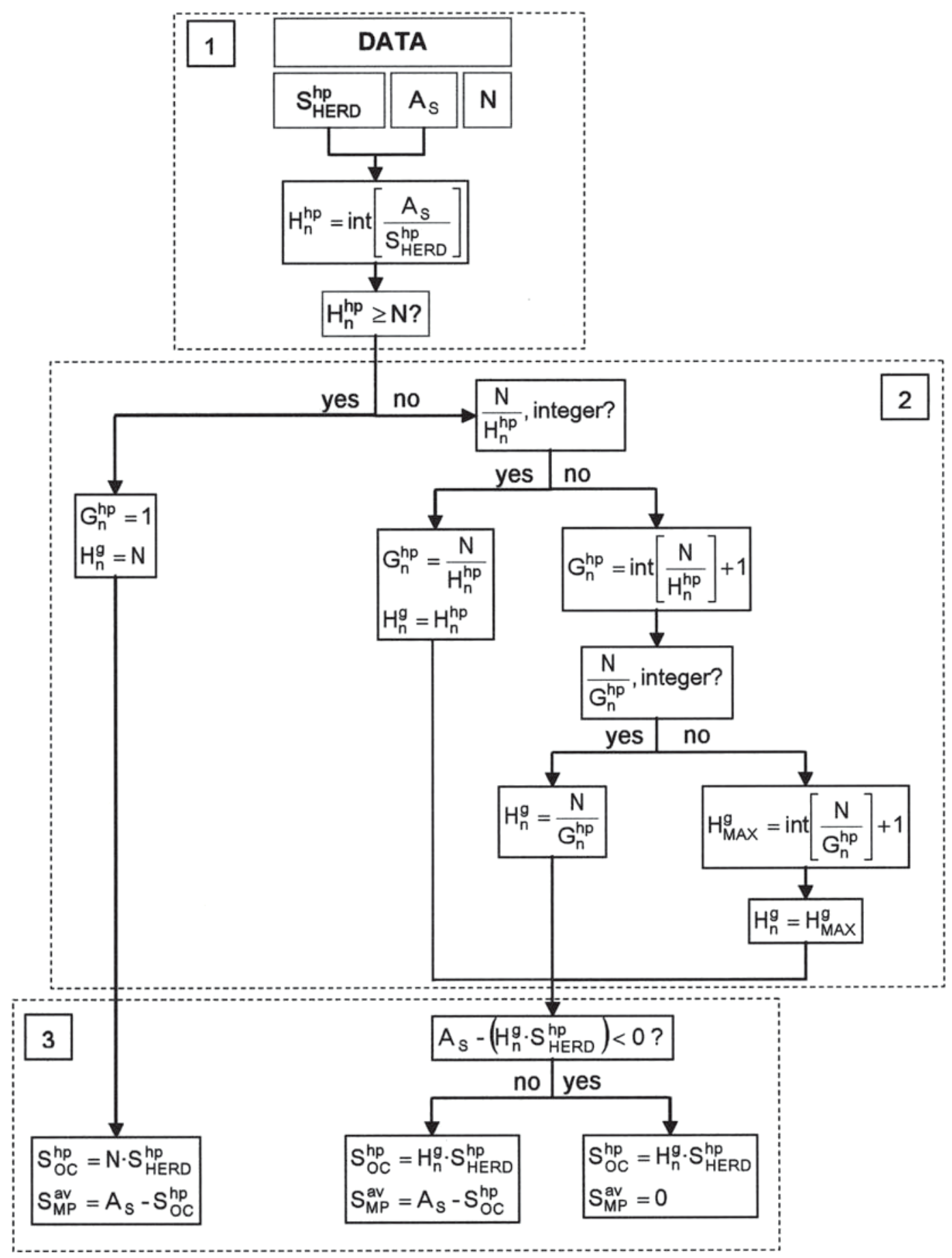

Figure 2. Algorithm for the design of the holding pen: $A_{S}=$ additional space for other areas (e. g. holding pen); $G_{n}{ }_{n}=$ number of groups of cows to milk; $\mathrm{H}_{\mathrm{MAX}}{ }^{\mathrm{g}}=$ maximum number of cows in the milking group; $\mathrm{H}_{\mathrm{n}}{ }^{\mathrm{g}}=$ number of cows per milking group; $\mathrm{H}_{\mathrm{n}}{ }^{\text {hp }}=$ maximum number of cows in the holding pen; $\mathrm{S}_{\mathrm{HERD}}{ }^{\mathrm{hp}}=$ minimum area per cow in the holding pen; $\mathrm{S}_{\mathrm{MP}}{ }^{\text {av }}=$ area available for the milking parlor; $\mathrm{S}_{\mathrm{OC}}{ }^{\text {hp }}=$ area occupied by the holding pen; $\mathrm{N}=$ herd size.

required when total milking time is greater than minimum milking time. Then, the algorithm checks whether the number of operators suggested is capable of managing those clusters by calculating lost time as the differ- ence between the work time available and the modified milking routine time. Lost time must be above zero. Otherwise (if modified milking routine time exceeds the work time available), the use of automatic cluster 


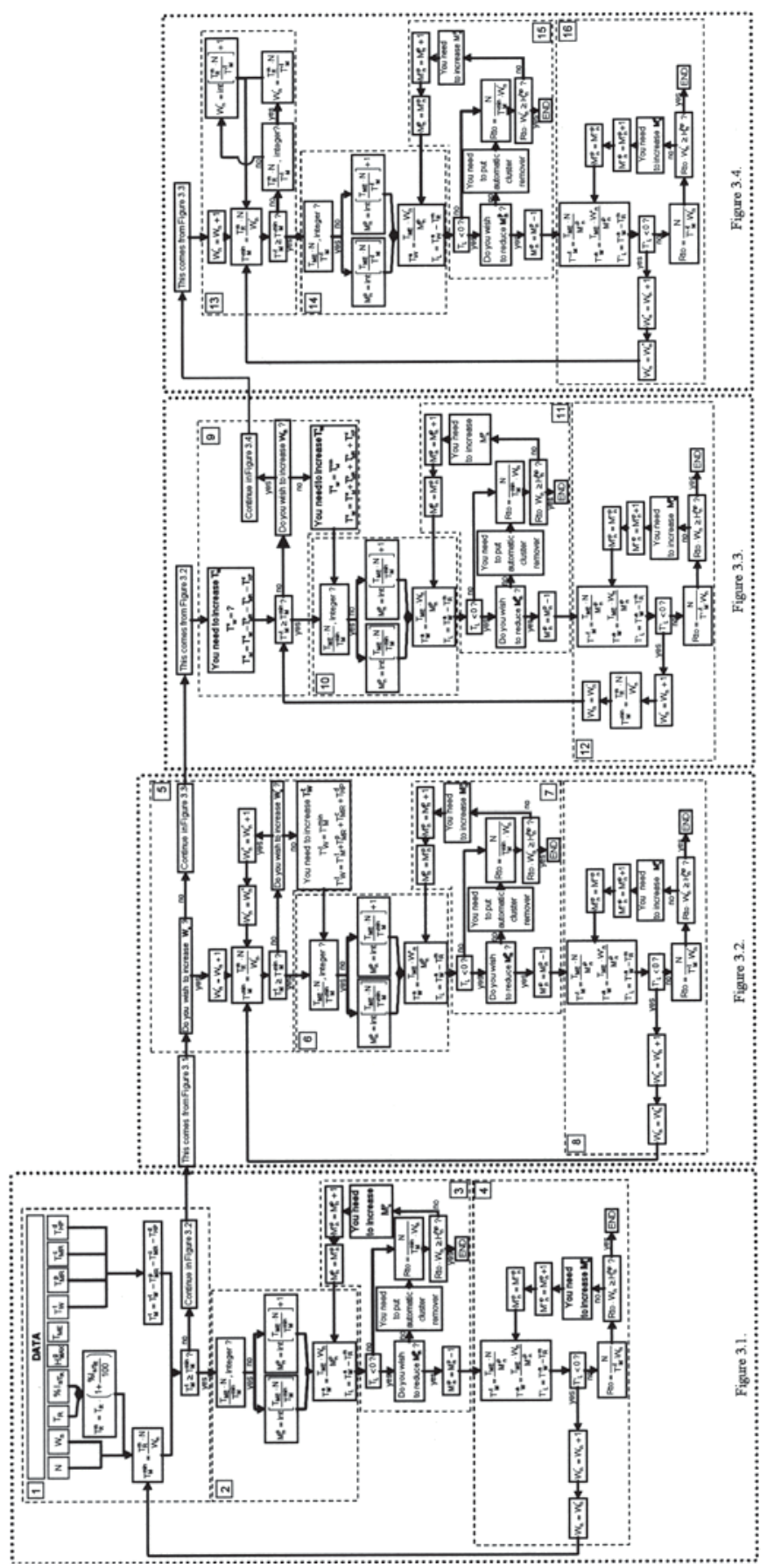

Figure 3. Algorithm for the design of the milking parlor: $\mathrm{M}_{\mathrm{n}}{ }^{\mathrm{p}}=$ number of milking clusters required; $\mathrm{N}=$ herd size; Rto = efficiency: number of cows milked per hour; $\mathrm{T}_{\mathrm{HP}}{ }^{\mathrm{d}}=$ time for driving the first group of cows into the holding pen; $\mathrm{T}_{\mathrm{L}}=$ lost time; $\mathrm{T}_{\mathrm{ME}}=$ milk removal time; $\mathrm{T}_{\mathrm{M}}$ min $=$ minimum milking time; $\mathrm{T}_{\mathrm{M}}{ }^{\mathrm{t}}=$ total milking time; $\mathrm{T}_{\mathrm{MR}}{ }^{\mathrm{c}}=$ time for cleaning the milking area; $\mathrm{T}_{\mathrm{MR}}{ }^{\mathrm{p}}=$ time for preparation of milking area before the milking; $\mathrm{T}_{\mathrm{R}}=$ milking routine time; $\mathrm{T}_{\mathrm{R}}{ }^{\mathrm{m}}=$ modified milking routine time; $\mathrm{T}_{\mathrm{W}}{ }^{\mathrm{a}}=$ work time available; $\mathrm{T}_{\mathrm{W}}{ }^{\mathrm{t}}=$ total working time; $\mathrm{W}_{\mathrm{n}}$ $=$ number of milkers in the milking operations; $\% \mathrm{l}_{\mathrm{s} / \mathrm{TR}}=$ time for contingencies expressed in percentage of the milking routine time. Note: Times measured in minutes. For readability, each panel is reproduced in the subparts of Figure 3.

removers or decreasing the number of milking points are suggested as alternatives.

The parts of Figure 3 are divided into sections that are numbered continuously (sections 1 to 16 ) through the algorithm because the whole algorithm pertains to the same area. To determine the dimensions of the milking parlor, the algorithm uses the parameters that are briefly described below: 


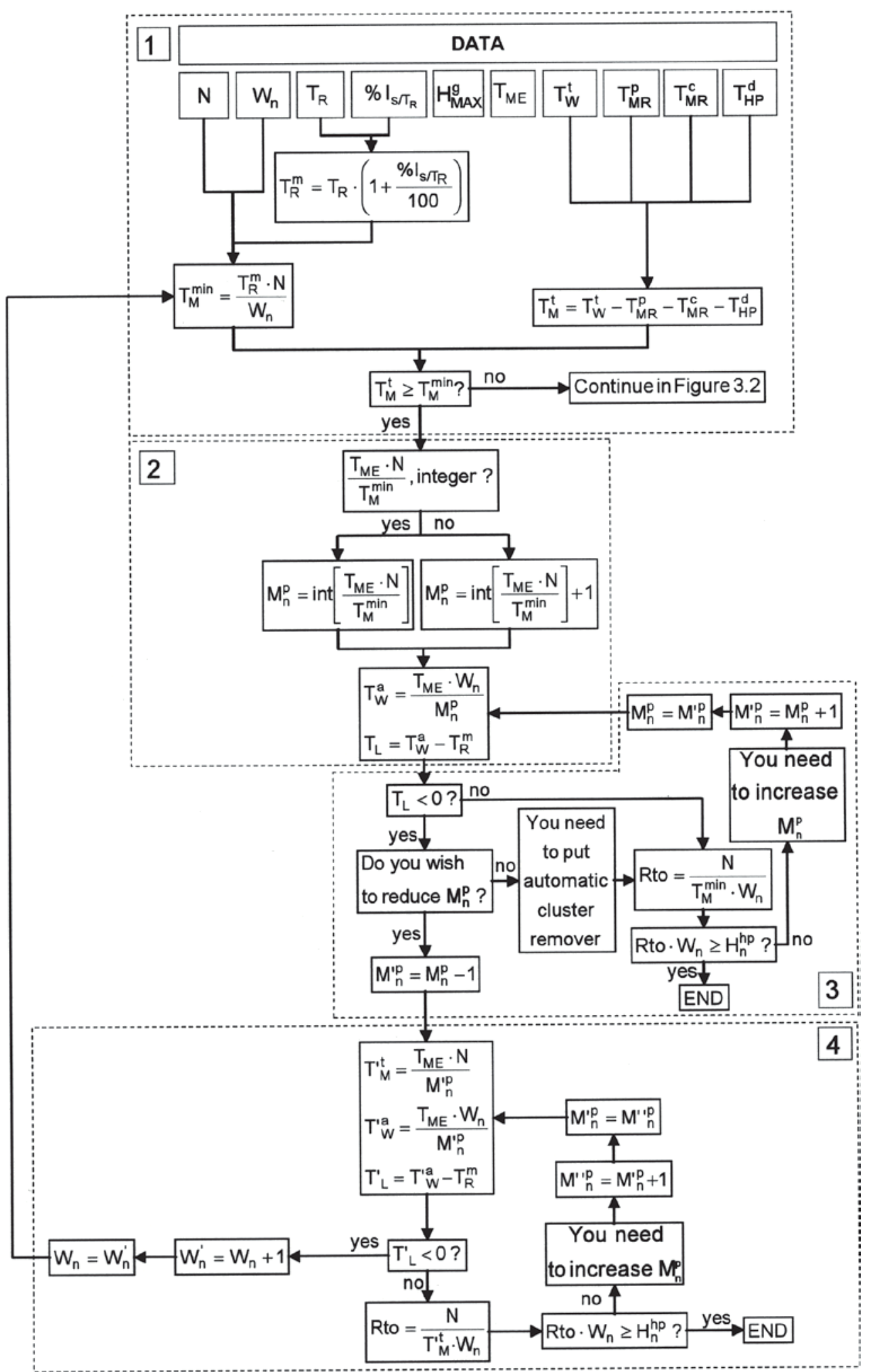

Figure 3.1. Algorithm for the design of the milking parlor, first scheme (panel 3.1): $\mathrm{M}_{\mathrm{n}}{ }^{\mathrm{p}}=$ number of milking clusters required; $\mathrm{N}=$ herd size; Rto = efficiency: number of cows milked per hour; $\mathrm{T}_{\mathrm{HP}}{ }^{\mathrm{d}}=$ time for driving the first group of cows into the holding pen; $\mathrm{T}_{\mathrm{L}}=$ lost time; $\mathrm{T}_{\mathrm{ME}}=$ milk removal time; $\mathrm{T}_{\mathrm{M}}{ }^{\text {min }}=$ minimum milking time; $\mathrm{T}_{\mathrm{M}}{ }^{\mathrm{t}}=$ total milking time; $\mathrm{T}_{\mathrm{MR}}{ }^{\mathrm{c}}=$ time for cleaning the milking area; $\mathrm{T}_{\mathrm{MR}}{ }^{\mathrm{p}}=$ time for preparation of milking area before the milking; $T_{R}=$ milking routine time; $T_{R}{ }^{m}=$ modified milking routine time; $T_{W}{ }^{a}=$ work time available; $\mathrm{T}_{\mathrm{W}}{ }^{t}=$ total working time; $\mathrm{W}_{\mathrm{n}}=$ number of milkers in the milking operations; $\% l_{\mathrm{s} / \mathrm{TR}}=$ time for contingencies expressed in percentage of the milking routine time. Note: Times measured in minutes. 


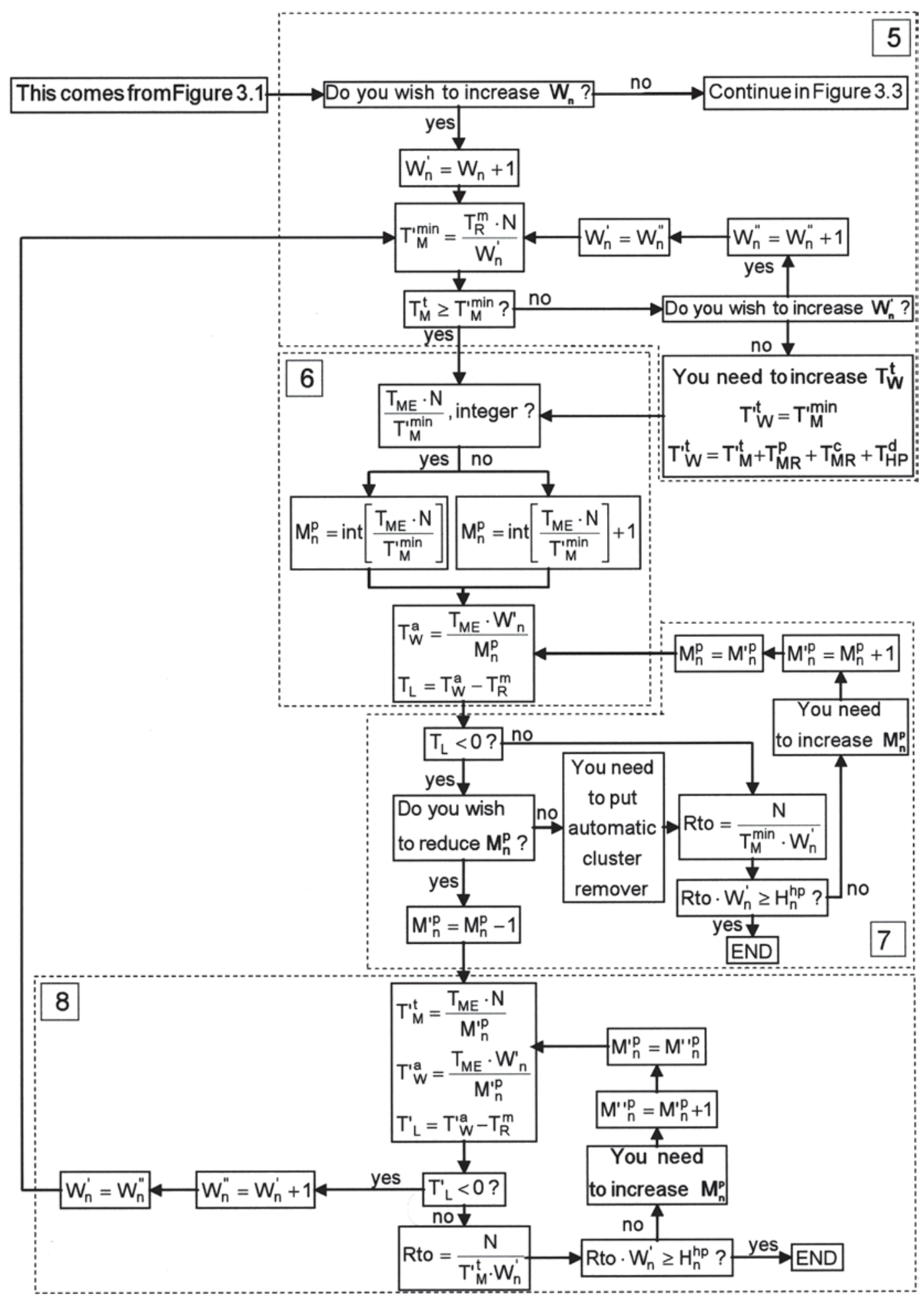

Figure 3.2. Algorithm for the design of the milking parlor, second scheme (panel 3.2): $\mathrm{M}_{\mathrm{n}}{ }^{\mathrm{p}}=$ number of milking clusters required; $\mathrm{N}=$ herd size; Rto = efficiency: number of cows milked per hour; $\mathrm{T}_{\mathrm{HP}}{ }^{\mathrm{d}}=$ time for driving the first group of cows into the holding pen; $\mathrm{T}_{\mathrm{L}}=$ lost time; $\mathrm{T}_{\mathrm{ME}}=$ milk removal time; $\mathrm{T}_{\mathrm{M}}{ }^{\min }=$ minimum milking time; $\mathrm{T}_{\mathrm{M}}{ }^{\mathrm{t}}=$ total milking time; $\mathrm{T}_{\mathrm{MR}}{ }^{\mathrm{c}}=$ time for cleaning the milking area; $\mathrm{T}_{\mathrm{MR}}{ }^{\mathrm{p}}=$ time for preparation of milking area before the milking; $\mathrm{T}_{\mathrm{R}}=$ milking routine time; $\mathrm{T}_{\mathrm{R}}{ }^{\mathrm{m}}=$ modified milking routine time; $\mathrm{T}_{\mathrm{W}}{ }^{\mathrm{a}}=\mathrm{work}{ }$ time available; $\mathrm{T}_{\mathrm{W}}{ }^{\mathrm{t}}=$ total working time; $\mathrm{W}_{\mathrm{n}}=$ number of milkers in the milking operations; $\% \mathrm{l}_{\mathrm{s} / \mathrm{TR}}=$ time for contingencies expressed in percentage of the milking routine time. Note: Times measured in minutes. 


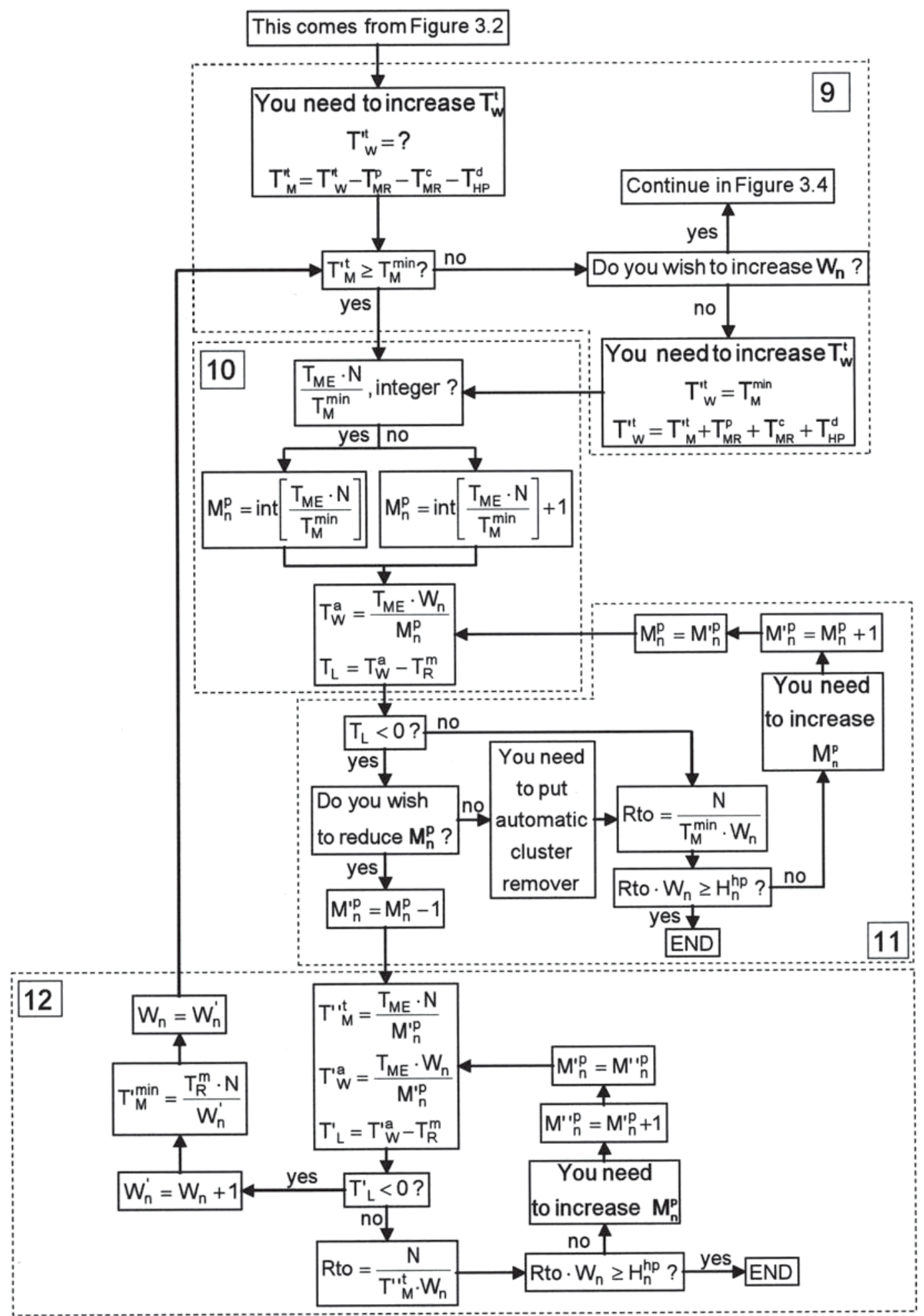

Figure 3.3. Algorithm for the design of the milking parlor, third scheme (panel 3.3): $\mathrm{M}_{\mathrm{n}}{ }^{\mathrm{p}}=$ number of milking clusters required; $\mathrm{N}=$ herd size; Rto = efficiency: number of cows milked per hour; $\mathrm{T}_{\mathrm{HP}}{ }^{\mathrm{d}}=$ time for driving the first group of cows into the holding pen; $\mathrm{T}_{\mathrm{L}}=$ lost time; $\mathrm{T}_{\mathrm{ME}}=$ milk removal time; $\mathrm{T}_{\mathrm{M}}{ }^{\mathrm{min}}=$ minimum milking time; $\mathrm{T}_{\mathrm{M}}{ }^{\mathrm{t}}=$ total milking time; $\mathrm{T}_{\mathrm{MR}}{ }^{\mathrm{c}}=$ time for cleaning the milking area; $\mathrm{T}_{\mathrm{MR}}{ }^{\mathrm{p}}=$ time for preparation of milking area before the milking; $T_{R}=$ milking routine time; $T_{R}{ }^{m}=$ modified milking routine time; $T_{W}{ }^{a}=$ work time available; $\mathrm{T}_{\mathrm{W}}{ }^{\mathrm{t}}=$ total working time; $\mathrm{W}_{\mathrm{n}}=$ number of milkers in the milking operations; $\% l_{\mathrm{s} / \mathrm{TR}}=$ time for contingencies expressed in percentage of the milking routine time. Note: Times measured in minutes. 


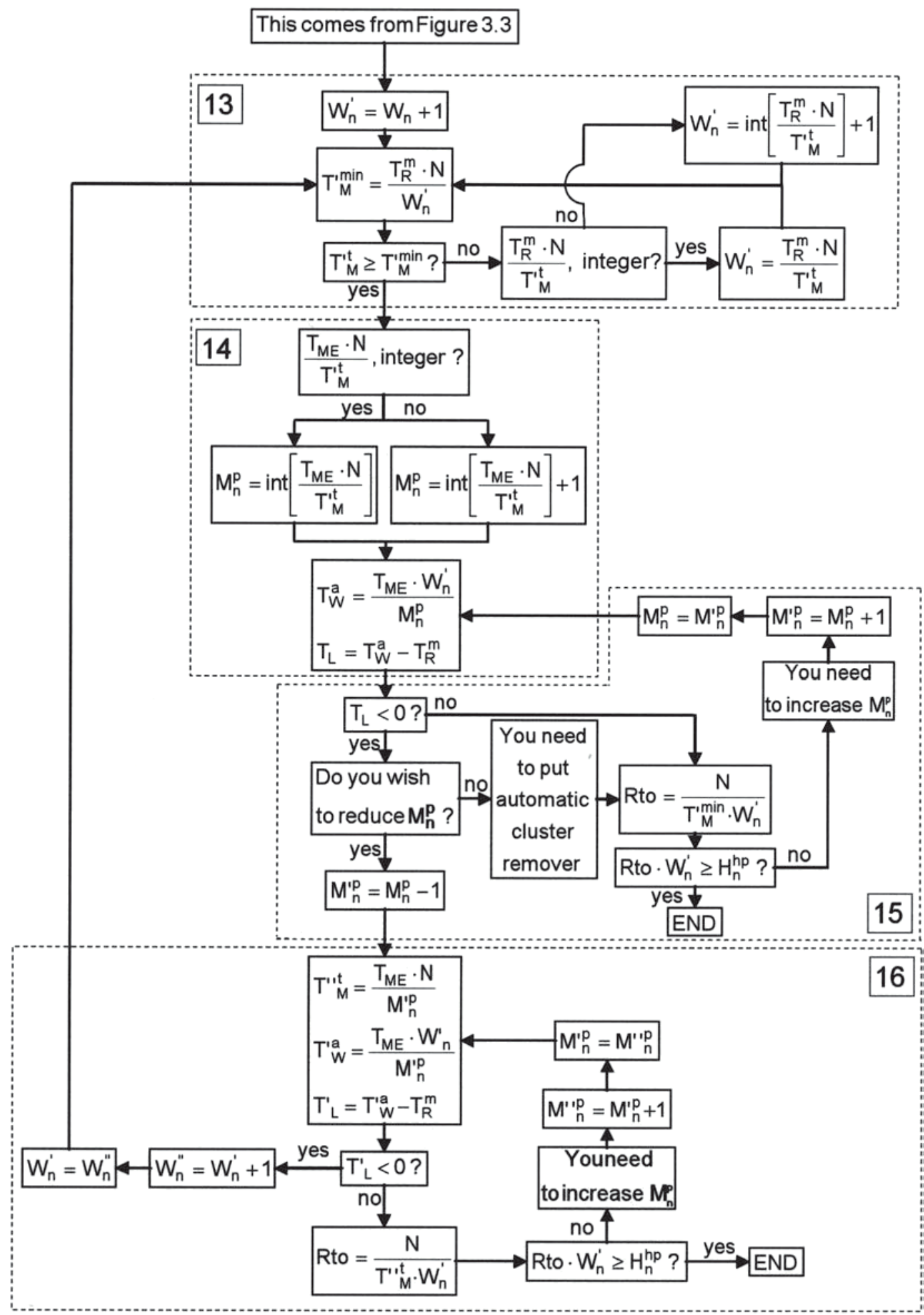

Figure 3.4. Algorithm for the design of the milking parlor, fourth and last scheme (panel 3.4): $\mathrm{M}_{\mathrm{n}}{ }^{\mathrm{p}}=$ number of milking clusters required; $\mathrm{N}=$ herd size; Rto $=$ efficiency: number of cows milked per hour; $\mathrm{T}_{\mathrm{HP}}{ }^{\mathrm{d}}=$ time for driving the first group of cows into the holding pen; $\mathrm{T}_{\mathrm{L}}=$ lost time; $\mathrm{T}_{\mathrm{ME}}=$ milk removal time; $\mathrm{T}_{\mathrm{M}}{ }^{\text {min }}=$ minimum milking time; $\mathrm{T}_{\mathrm{M}}{ }^{\mathrm{t}}=$ total milking time; $\mathrm{T}_{\mathrm{MR}}{ }^{\mathrm{c}}=$ time for cleaning the milking area; $\mathrm{T}_{\mathrm{MR}}{ }^{\mathrm{p}}$ $=$ time for preparation of milking area before the milking; $\mathrm{T}_{\mathrm{R}}=$ milking routine time; $\mathrm{T}_{\mathrm{R}}{ }^{\mathrm{m}}=$ modified milking routine time; $\mathrm{T}_{\mathrm{W}}{ }^{\mathrm{a}}=$ work time available; $\mathrm{T}_{\mathrm{W}}{ }^{\mathrm{t}}=$ total working time; $\mathrm{W}_{\mathrm{n}}=$ number of milkers in the milking operations; $\% l_{\mathrm{s} / \mathrm{TR}}=$ time for contingencies expressed in percentage of the milking routine time. Note: Times measured in minutes. 
- Number of milking points or clusters: number of clusters in the milking parlor;

- Operators involved: number of people involved in the milking;

- Milking routine time: time spent by one person to complete the operations included in the milking routine for one cow;

- Modified milking routine time: milking routine time increased by a percentage for unexpected or emergency tasks;

- Milk removal time or milk flow: time required to extract milk after clusters have been attached;

- Cluster idle time: delay between the time a cow is prepared and cluster attachment;

- Cluster time (milk removal time plus cluster idle time): time during which a cluster is attached to a cow, increased by cluster idle time;

- Work time available: time available for milking operations per cow per milker;

- Total milking time: time spent between the start of milking operations and the completion of milking operations;

- Overall work time: milking time plus time devoted to other tasks related to each milking (preparing the parlor, driving cows to the holding pen, among others); and

- Efficiency: number of cows milked per hour.

In panel 3.1 of Figure 3, the time available to milk the herd is calculated from the input data, and the minimum time required by milkers to milk the whole herd is determined (overall work time minus time devoted to other tasks related to each milking and modified milking routine time multiplied by the number of cows and divided by the number of operators, respectively). The algorithm uses the "modified milking routine time" parameter because it takes into consideration any contingency that may affect milking routine time. To end this section, the algorithm compares both values to verify that milking can be performed using input data. If milking operations can be carried out according to the input data, the algorithm continues in Figure 3, panel 3.1 (section 2). Otherwise, the algorithm continues in Figure 3 panel 3.2 (section 5) to increase the number of operators.

Section 2 calculates the number of milking points required to milk the herd according to the routine scheduled, rounding off the number to the nearest integer, if necessary. In addition, the work time available to complete the milking routine for each cow and lost time (computed as the difference between work time available and modified milking routine time) are calculated. The work time available is calculated by dividing the product of milk removal time and number of cows by the number of milking points. If the work time available exceeds the modified milking routine time, the operator has enough time to care for every cow (lost time is above zero). If the work time available is shorter than the modified milking routine time, the operator does not have enough time to care for every cow and overmilking of the cows that are being milked occurs (lost time is below zero).

In section 3, a loop is included to check whether the milker has enough time to care for the cows. If the milker has enough time available (lost time is greater than zero), the milking efficiency per parlor is computed and the process is completed by checking that the time spent by the milking herd in the holding pen is not exceeded (if the time spent by the milking herd in the holding pen is exceeded, it is recommended to increase the number of milkers and check the times again). If the milker does not have enough time to care for one cow, overmilking of the cow that is being milked simultaneously occurs (time available for the milking routine or work time available $<$ modified milking routine time). A possible solution would involve the use of automatic cluster removers. The cycle ends after the efficiency of the parlor is calculated. Another solution is reducing the number of milking points managed by each milker, such that the milker has enough time to care for all the cows.

Section 4 computes the times (total milking time, work time available, and lost time) after having decreased the number of milking points in the cluster. The sequence ends by checking whether overmilking occurs. If overmilking does not occur, milking efficiency is obtained, and the algorithm checks the time spent by the milking group in the holding pen. If overmilking occurs, the number of milkers is increased by 1 and a loop goes back to the beginning of the sequence.

The algorithm continues in Figure 3 panel 3.2 if milking cannot be carried out according to the input data. To satisfy the demand for labor generated by the input data, this section of the algorithm assesses the possibility of increasing the number of people involved in milking operations. If the number of people is not increased, the algorithm continues in Figure 3, panel 3.3. However, if the user decides to increase the number of milkers, the algorithm calculates (in section 5) the minimum time required to milk the cows and checks again whether the milking operations can be performed under such conditions. For that purpose, a loop is included that allows the user to increase the number of milkers again (if necessary) or to increase total work time. Sections 6,7 , and 8 of the algorithm work like sections 2,3 , and 4 , respectively, in panel 3.1. If the milking can be carried out, the number of units and lost time are calculated (section 6 ). If lost time is above 
Table 1. Results for a 2-row tail-to-tail design with maternity pens arranged in rows

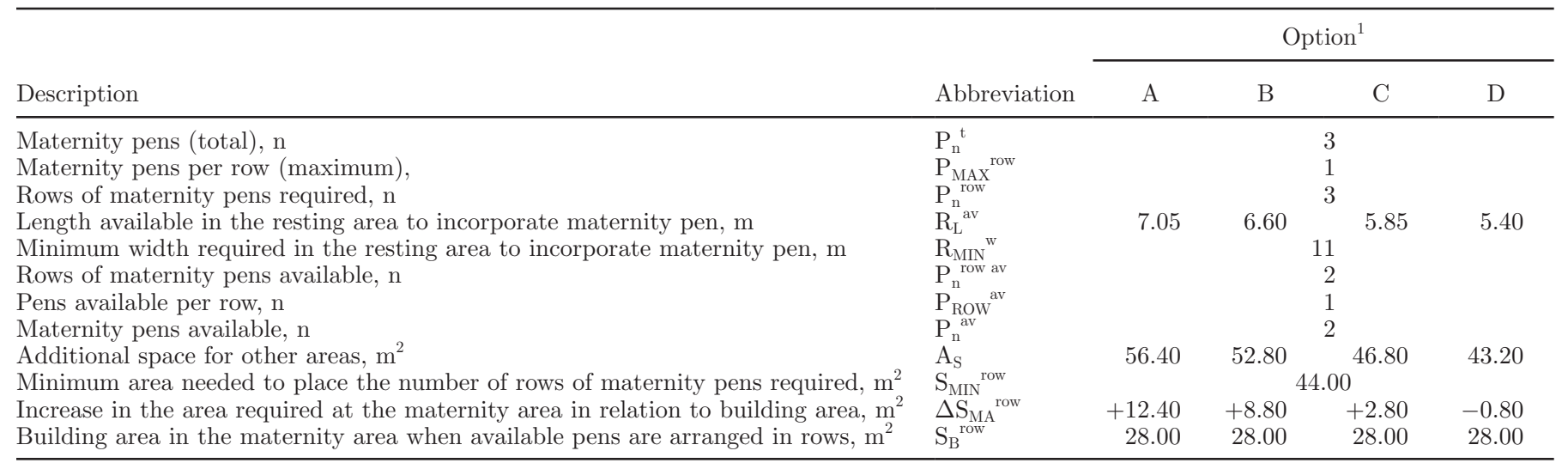

${ }^{1} \mathrm{~A}=$ all cross alleys without waterers; $\mathrm{B}=1$ cross alley with waterer; $\mathrm{C}=2$ cross alleys with waterers; and $\mathrm{D}=$ all cross alleys with waterers.

zero, the milking efficiency of the parlor is calculated. If lost time is negative, it is recommended to decrease the number of milking points or to install automatic cluster removers (section 7). If the number of milking points is decreased, times (total milking time, work time available, and lost time) must be checked again in section 8.

If the user decides not to increase the number of milkers in section 5 (panel 3.2; Figure 3), the only option to milk the herd by using the input data is to increase total work time. To increase total work time, the algorithm goes to panel 3.3 section 9 , where it checks whether the milker can care for the cows within the new milking time. If this is not possible, a loop that allows the user to increase the number of milkers (going to panel 3.4) or the total work time is included. Sections 10, 11, and 12 work like sections 2,3 , and 4 , respectively, of panel 3.1 .
If the user decides to increase the number of milkers to milk the herd according to the input data (section 9), the algorithm goes to section 13 of panel 3.4. Section 13 calculates the minimum time required for milking after having increased the number of milkers by 1 . Then, the algorithm checks whether the total time required to milk the herd is below the minimum time. If so, section 14 of the algorithm is entered. If the total time required to milk the herd exceeds the minimum time, a loop is added to increase the number of milkers again until the total time required to milk the herd does not exceed the minimum time. Sections 14, 15, and 16 work like sections 2,3 , and 4 , respectively, of panel 3.1. The algorithm designed to determine the number of milking points in the milking parlor ends here.

The algorithms described above analyze the possibility of incorporating the maternity and milking areas in the same building as the resting, feeding, and exercise

Table 2. Results for a 2-row tail-to-tail design with maternity pens arranged in columns

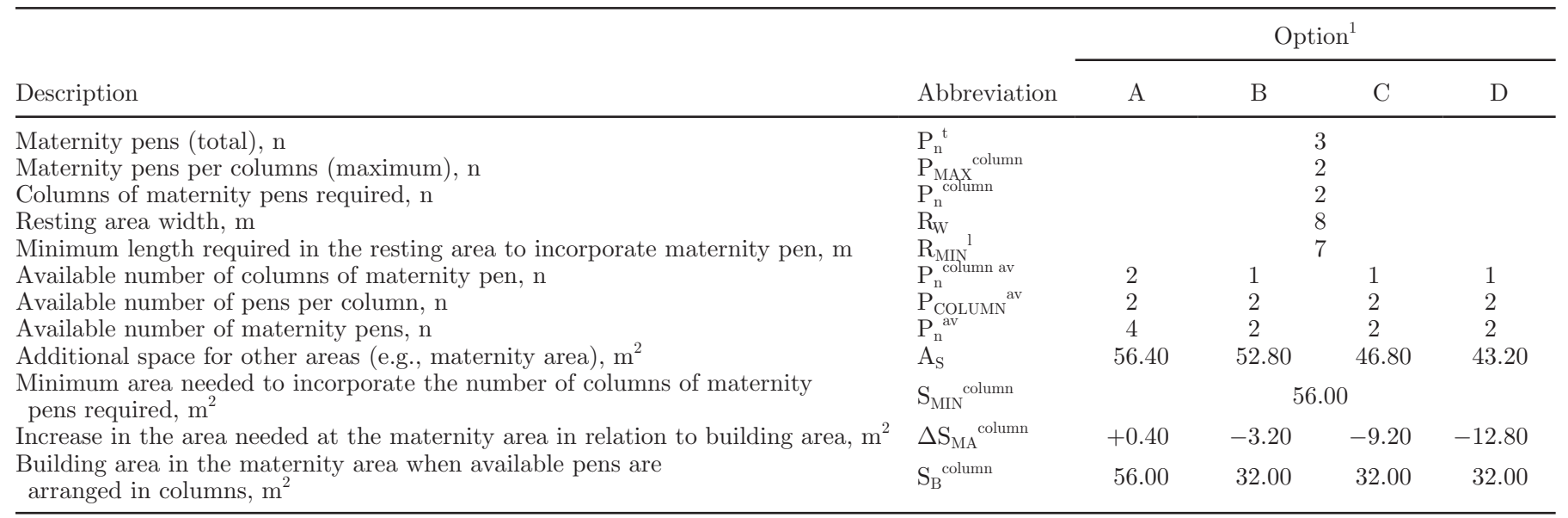

${ }^{1} \mathrm{~A}=$ all cross alleys without waterers; $\mathrm{B}=1$ cross alley with waterer; $\mathrm{C}=2$ cross alleys with waterers; and $\mathrm{D}=$ all cross alleys with waterers. 


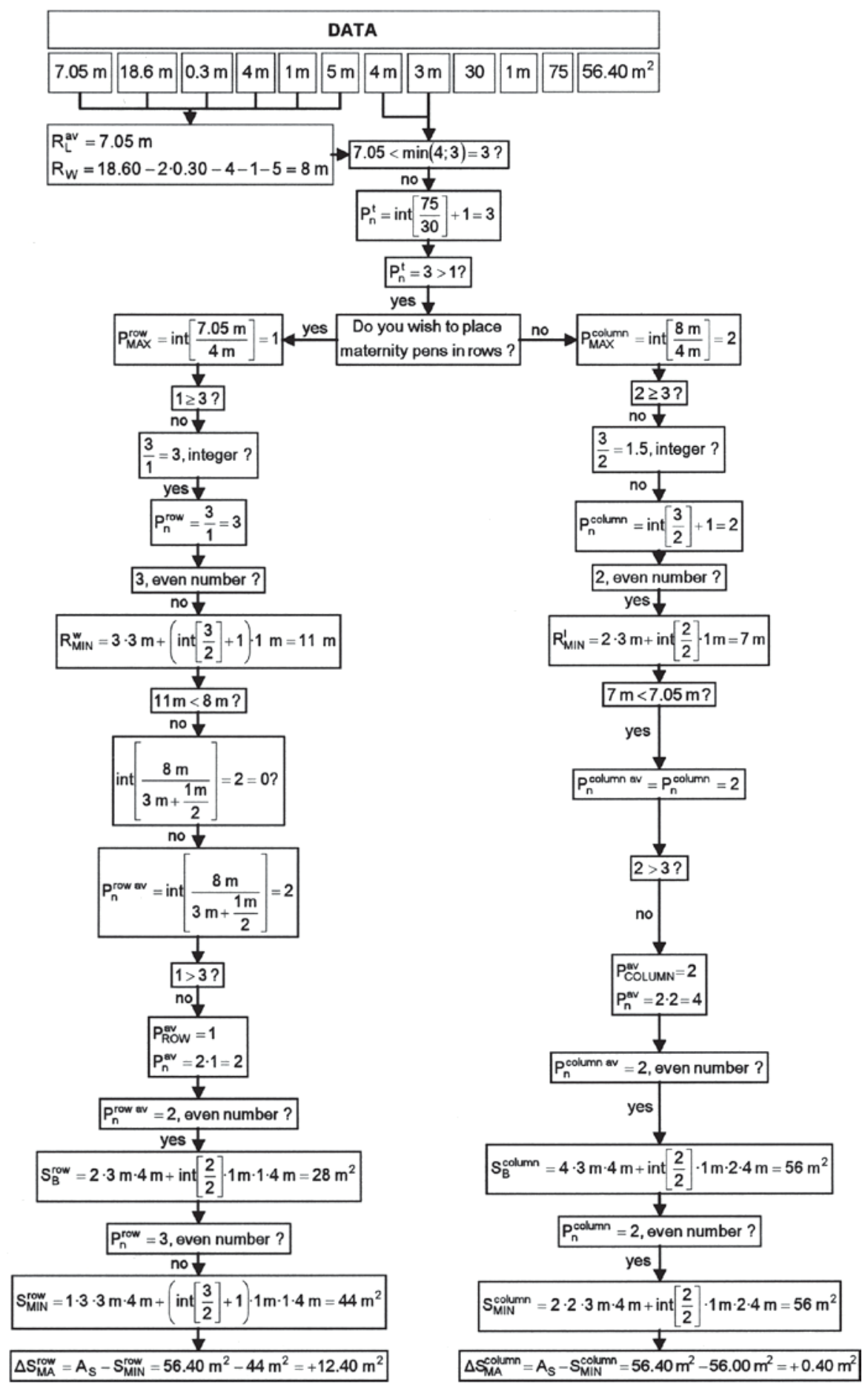

Figure 4. Working steps of the algorithm for the design of the calving area: $A_{S}=$ additional space for other areas (e. g. maternity or calving area) $; \mathrm{P}_{\text {COLUMN }}{ }^{\text {av }}=$ available number of pens per row; $\mathrm{P}_{\mathrm{MAX}}{ }^{\text {column }}=$ maximum number of maternity pens in each column; $\mathrm{P}_{\mathrm{MAX}}{ }^{\text {row }}=$ maximum number of maternity pens in each row; $\mathrm{P}_{\mathrm{n}}{ }^{\text {av }}=$ available number of maternity pens; $\mathrm{P}_{\mathrm{n}}$ column $=$ number of columns of maternity pens required; $\mathrm{P}_{\mathrm{n}}^{\text {column av }}=$ available number of columns of maternity pens; $\mathrm{P}_{\mathrm{n}}^{\text {row }}=$ number of rows of maternity pens required; $\mathrm{P}_{\mathrm{n}}{ }^{\text {row av }}=$ available number of rows of maternity pens; $\mathrm{P}_{\mathrm{n}}{ }^{\mathrm{t}}=$ total number of maternity pens; $\mathrm{P}_{\mathrm{ROW}}{ }^{\text {av }}=$ available number of pens per row; $\mathrm{R}_{\mathrm{L}}{ }^{\mathrm{av}}=$ available length in the resting area to place maternity pens; $\mathrm{R}_{\mathrm{MIN}}{ }^{1}=$ minimum length required in the resting area; $\mathrm{R}_{\mathrm{MIN}}{ }^{\mathrm{w}}=$ minimum width required in the resting area; $\mathrm{R}_{\mathrm{W}}$ $=$ resting area width (including free stall alley width); $\mathrm{S}_{\mathrm{B}}{ }^{\text {column }}=$ building area in the maternity for pens arranged in columns; $\mathrm{S}_{\mathrm{B}}{ }^{\text {row }}=$ building area in the maternity for pens arranged in rows; $\mathrm{S}_{\mathrm{MIN}}{ }^{\text {column }}=$ minimum area needed to place the number of columns of maternity pens required; $\mathrm{S}_{\mathrm{MIN}}{ }^{\text {row }}=$ minimum area needed to place the number of rows of maternity pens required; $\Delta \mathrm{S}_{\mathrm{MA}}{ }^{\text {column }}=$ increase in the area needed in the maternity with respect to the building area for maternity pens arranged in columns; $\Delta \mathrm{S}_{\mathrm{MA}}{ }^{\text {row }}=$ increase in the area needed in the maternity with respect to the building area for maternity pens arranged in rows. 


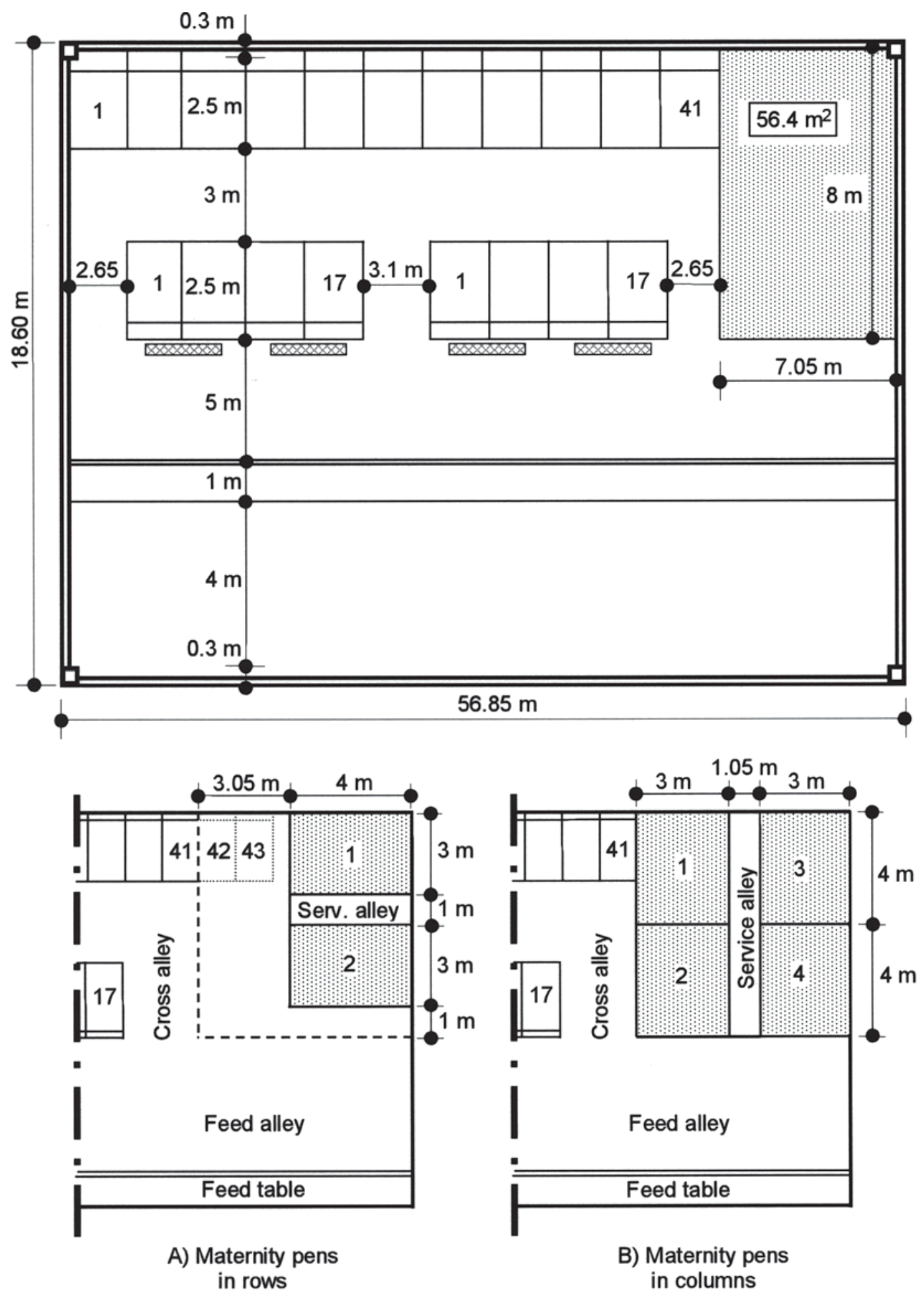

Figure 5. Graphical example for the design of the calving area. Serv.= service.

areas, and complement the algorithms for the design of the resting, feeding, and exercise areas insofar as they allow the user to assess the possibility of using an area according to the dimensions of the internal distribution elements. The algorithms described above have been developed by using flowcharts that represent the design process for each part of the algorithm in order that they can be implemented within a software application. The 


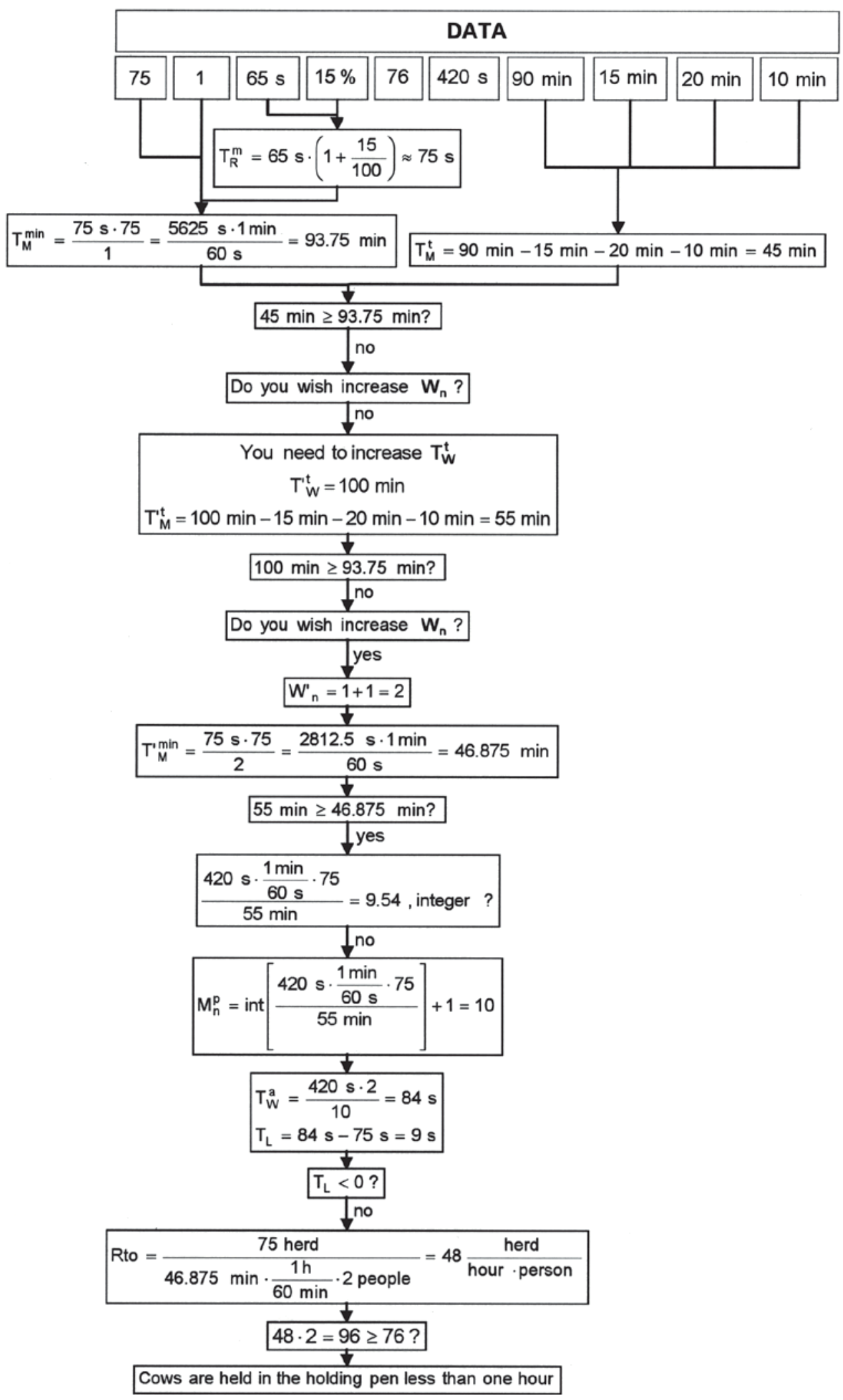

Figure 6. Working steps of the algorithms for the design of the milking area: $\mathrm{M}_{\mathrm{n}}{ }^{\mathrm{p}}=$ number of milking clusters required; $\mathrm{T}_{\mathrm{L}}=$ lost time;

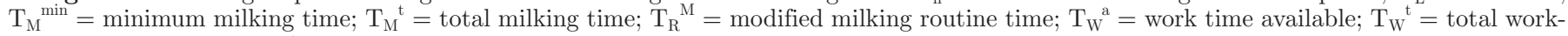
ing time; $\mathrm{W}_{\mathrm{n}}=$ number of milkers in the milking operations. Note: Times measured in minutes. 
Table 3. Comparison of final designs with waterers in all cross alleys for the incorporation of the milking area

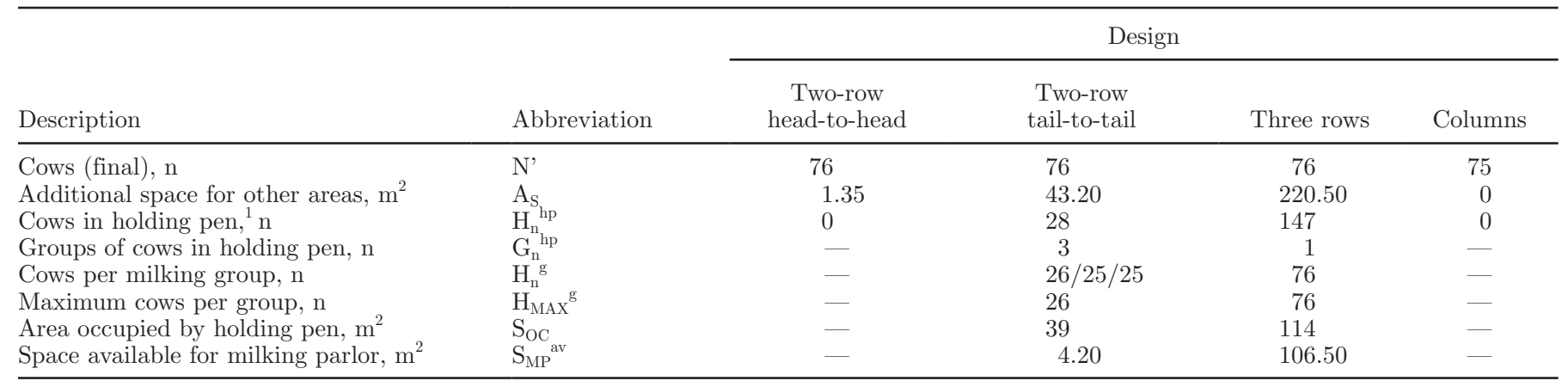

${ }^{1}$ Ratio $1.5 \mathrm{~m}^{2} /$ cow.

steps of the design process have been included. Thus, the algorithm starts with some input data and allows the user to follow preset paths to make the design decisions that lead to a specific layout solution.

The results obtained using this algorithm is presented by way of an example. The example below follows the example provided in Fernández et al. (2006), for a 2 -row tail-to-tail arrangement. The values of the input parameters used were as follows: herd size $=75$; free stalls per cow $=1$; feeding places per cow $=1$; width of cross alleys without waterers $=2.65 \mathrm{~m}$; width of cross alleys with waterers $=3.75 \mathrm{~m}$; maximum number of contiguous stalls $=25$; stall width $=1.20 \mathrm{~m}$; stall length $=2.50 \mathrm{~m}$; space per cow at the feeding barrier $=$ $0.75 \mathrm{~m} ; 1$ waterer per group of 20 cows; no concentrate feeders. The other parameters required to define the final dimensions were driveway width $(4.00 \mathrm{~m})$; feeding surface width $(1.00 \mathrm{~m})$; feed alley width with waterers $(5.00 \mathrm{~m})$; feed alley width without waterers for feed alley, movement and access to stalls $(4.50 \mathrm{~m})$; free-stall alley width behind or between free-stall rows without waterers $(3.00 \mathrm{~m})$ or with waterers $(4.00 \mathrm{~m})$; and column width $(0.30 \mathrm{~m})$. These data were used to obtain the following data pertaining to barn layout: increase in resting area length $=7.05 \mathrm{~m}$; total outside barn width $=18.6 \mathrm{~m}$; and additional space for other areas $=56.40 \mathrm{~m}^{2}$. Input data for the calving area were the following: length of maternity pen $=4.0 \mathrm{~m}$; width of maternity pen $=3.0 \mathrm{~m}$; number of cows per maternity pen $=30$; and service alley width (placed between rows of columns of maternity pens) $=1.0 \mathrm{~m}$. To make the use of the algorithms easier, several spreadsheets were developed by using Excel (Microsoft Corp., Redmond, WA). The steps that compose the algorithms were introduced in the spreadsheets such that the results could be readily obtained and the operational management of the algorithms was improved.

The results for the design of the maternity area are shown in Table 1 (pens arranged in rows) and Table 2 (pens arranged in columns). Tables 1 and 2 summarize data pertaining to the design of the maternity area, such as the number of rows or columns required to fit all the pens required according to the input data or the number of rows or columns that can actually be included in the area according to the dimensions of the space available. In addition, these tables show the area required, the area available in the space adjacent to the resting area, and the comparison of both values. As shown in Table 1, the space available is not enough to incorporate the 3 calving pens required because 3 rows

Table 4. Comparison of final designs without waterers in cross alleys for the incorporation of the milking area

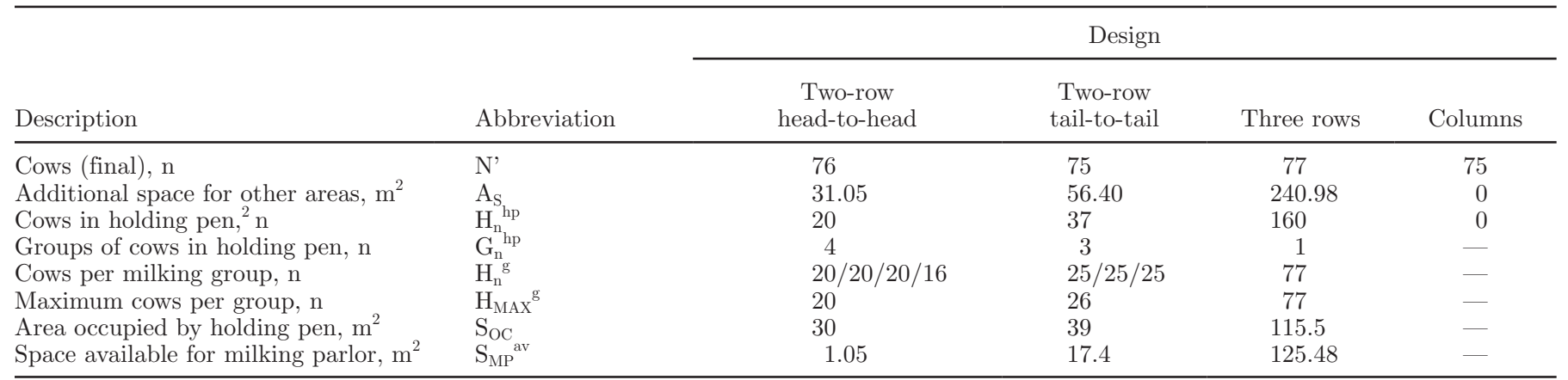

${ }^{1}$ Ratio $1.5 \mathrm{~m}^{2} /$ cow. 


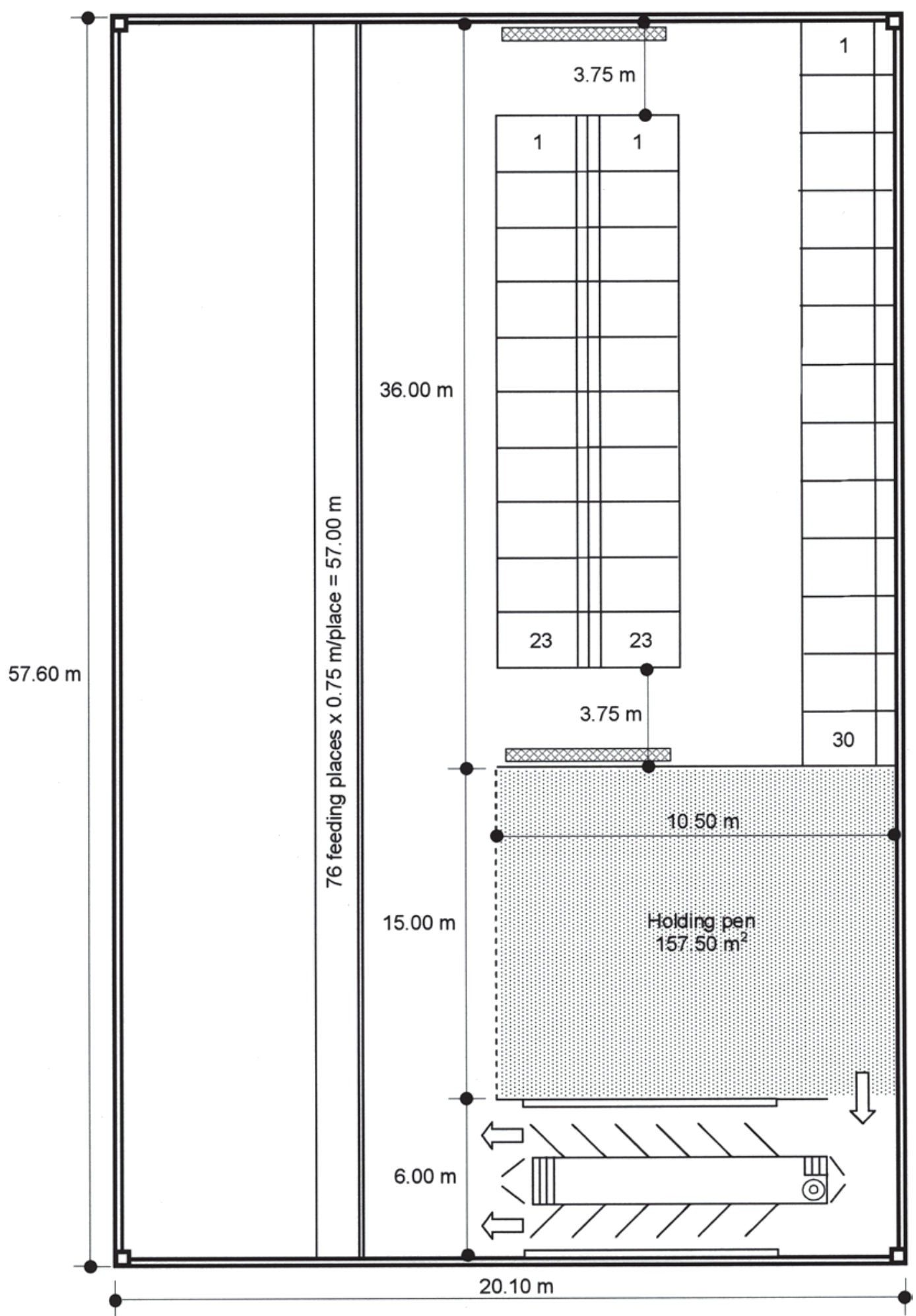

Figure 7. Example of a solution for the distribution of the space available in the 3-row design. 
Table 5. Data of milking parlor dimensions to complete the analysis for the incorporation of the milking area (from DeLaval, 2008)

\begin{tabular}{|c|c|c|c|c|c|}
\hline Description & \multicolumn{5}{|c|}{ Milking parlor } \\
\hline Milking points, $\mathrm{n}$ & $2 \times 5$ & $2 \times 5$ & $2 \times 5$ & $2 \times 5$ & $1 \times 10$ \\
\hline Stall width, m & $1.15^{1}$ & $0.80^{1}$ & $0.85^{2}$ & $0.70^{1}$ & $0.70^{1}$ \\
\hline Pit width, ${ }^{3} \mathrm{~m}$ & 2.00 & 2.00 & 2.00 & 2.30 & 2.30 \\
\hline$\Delta$ Pit length, ${ }^{4} \mathrm{~m}$ & 2.10 & 2.10 & 2.20 & 2.25 & 2.25 \\
\hline Total length, ${ }^{5} \mathrm{~m}$ & 9.95 & 8.20 & 16.90 & 8.00 & 11.50 \\
\hline$\Delta$ Total length, ${ }^{6} \mathrm{~m}$ & 1.00 & 1.00 & 1.00 & 2.00 & 2.00 \\
\hline Area occupied by the milking parlor, $\mathrm{m}^{2}$ & 49.75 & 49.20 & 91.26 & 90.40 & 78.20 \\
\hline
\end{tabular}

${ }^{1}$ Measured parallel to the pit.

${ }^{2}$ Measured perpendicular to the pit.

${ }^{3}+0.5 \mathrm{~m}$ including milk receiver.

${ }^{4}$ To fit access stairs and final cluster.

${ }^{5}$ With front entrance or exit.

${ }^{6}$ With side entrance or exit.

of pens with 1 pen per row would be needed, and there is room for only 2 pens. The space available would be sufficient for 2 pens except for a layout with waterers along cross alleys. The same pattern is repeated for the option with pens arranged in columns (Table 2): only 2 calving pens could be incorporated in the area, except for option A (cross alleys without waterers), which would admit 2 columns of pens. Figure 4 illustrates the use of the algorithm (Figure 1) and the results for option A of Table 1. Figure 5 shows the graphical representation of the results obtained for option A for pens arranged in rows (Table 1) and for pens arranged in columns (Table 2). The layout with pens arranged in columns (B) allows for the use of the space adjacent to the resting area, such that 4 pens ( 2 columns) can be incorporated in the area, even though 3 pens would suffice according to the input data (30 cows per pen). However, the layout with pens arranged in rows does not allow for the incorporation of the maternity area in the space available according to the input data.

For the design of the milking area, the following data were considered: number of workers participating in milking operations $=1$; milking routine time $=65 \mathrm{~s}$; percentage increase in milking routine time for contingencies $=15 \%$; milk removal time $=420 \mathrm{~s}$; total work time $=90 \mathrm{~min}$; time for the preparation of the milking area $=15 \mathrm{~min}$; time for the cleaning of the milking area $=20 \mathrm{~min}$ and time for driving the first group of cows into the holding pen $=10 \mathrm{~min}$.

Figure 6 illustrates how the algorithm for the design of the milking area is used to obtain the number of milking points based on input data. Because milking operations cannot be performed according to the input data defined, total milking time is increased from 90 to
100 min. Still, milking operations cannot be performed. By increasing the number of milkers to 2, milking operations can be performed using the input data. The result is a milking parlor with 10 milking points.

Table 3 follows the example presented in Fernández et al. (2006), considering the results for the different barn layout designs (2-row head-to-head barn, 2-row tail-to-tail barn, 3-row barn, and barn with perpendicular rows). Table 3 summarizes the assessment of the space adjacent to the resting area for the incorporation of a milking area for 75 cows under the assumption that there are waterers in every cross alley. The 3-row design can house a holding pen for only one milking group and has enough space available for the milking parlor. The 2-row tail-to-tail design can house a smaller holding pen. The other 2 designs, 2-row head-to-head and columns do not have enough space available.

Table 4 summarizes the assessment of the space adjacent to the resting area for a barn design without waterers along the cross alleys. Under this assumption, the 2-row head-to-head arrangement also allows for the incorporation of a holding pen, which is smaller than the holding pen included in the 2-row tail-to-tail barn and in the 3-row barn.

Finally, Table 5 includes data pertaining to the dimensions of the milking parlor according to the results obtained from the algorithm illustrated in Figure 6 . Such data have been taken from a commercial cata$\log$ of a company that manufactures milking parlors (DeLaval, 2008). Data pertaining to parlor dimensions have been used to assess how the space adjacent to the resting area can be used. In this case, 4 types of milking parlor have been assessed: herringbone $30^{\circ}$, herringbone $50^{\circ}$, tandem, and parallel parlors. The widest 
parlors are parallel parlors, whereas the narrowest are herringbone $50^{\circ}$ milking parlors. With regard to length, the longest parlors are herringbone $30^{\circ}$ parlors and the shortest are parallel parlors. By using data shown in Tables 3, 4, and 5 the space required for the milking parlor can be compared with the space left after having subtracted the area occupied by the holding pen. Such a comparison allows the user to define possible layout designs, such that the different designs can be assessed in terms of advantages and disadvantages. In our example, the 3-row design is the only layout design that allows for the integration of the holding pen and the milking parlor in the space adjacent to the resting area. Figure 7 graphically represents one of the possible layout solutions for the example developed here, a herringbone $50^{\circ}$ milking parlor. In this case, the area is used properly, but the side entrance to the milking parlor is not recommended. Therefore, the user should assess other options such as a parallel parlor.

\section{CONCLUSIONS}

The algorithms developed in this article provide a tool to obtain layout solutions for the maternity and milking areas of a barn. The algorithms allow the user to analyze both areas by considering different input values for the parameters related to barn layout. In addition, the algorithms presented enable space optimization insofar as they provide solutions for each particular case. The algorithms developed can be used to obtain different layout solutions and favor the assessment of the designs to achieve a valid final solution that considers criteria related to cow welfare and ease of management. Accordingly, such algorithms allow for the use of input data aimed at favoring such aspects. Finally, these algorithms can be implemented in computer software, which makes the use of the algorithms easier. The implemented algorithms can be used as a support tool for the design of free-stall barns for dairy cattle.

\section{REFERENCES}

Anonymous. 2001. Interdisciplinary report: Housing Design for Cattle - Danish Recommendations. 3rd ed. The Danish Agricultural Advisory Center, Aarhus, Jutland, Denmark.

Bickert, W. G., B. Holmes, K. Janni, D. Kammel, R. Stowell, and J. Zulovich. 2000. Dairy Free Stall Housing and Equipment. 7th ed. MidWest Plan Service, Iowa State University, Ames.

BTPL (Bureau Technique de Promotion Laitière). 2005. Le logement du troupeau laitier. 2nd ed. Editions France Agricole, Paris, France.

Burks, T. F., L. W. Turner, and W. L. Crist. 2006. Distribution fitting and parameterization of individual work routine times for small dairy parlors. J. Dairy Sci. 89:2343-2352.
Carreira Pérez, X. C. 1996. Aloxamentos para gando vacún de leite. Consellería de Agricultura, Gandería e Montes, Xunta de Galicia, Santiago de Compostela, Spain.

Cooper, M. D., D. R. Arney, and C. J. C. Phillips. 2007. Two- or fourhour lying deprivation on the behavior of lactating dairy cows. J. Dairy Sci. 90:1149-1158.

DeLaval. 2008. Solutions for Milking. Catalogs available online: http://www.delaval.com/Products/Milking/default.htm. Accessed May, 2. 2008

DeVries, T. J., and M. A. G. von Keyserlingk. 2006. Feed stalls affect the social and feeding behaviour of lactating dairy cows. J. Dairy Sci. 89:3522-3531.

DeVries, T. J., M. A. G. von Keyserlingk, and D. M. Weary. 2004 Effect of feeding space on the inter-cow distance, aggression, and feeding behaviour of free-stall housed lactating dairy cows. J. Dairy Sci. 87:1432-1438.

Fernández, M. E., R. A. Mariño, and X. C. Carreira. 2006. Algorithms for dairy barn design: Resting, feeding and exercise. J. Dairy Sci. 89:2784-2798.

Fernández, M. E., R. A. Mariño, and X. C. Carreira. 2008. Relationship between layout and timber structures in freestall dairy cattle barns: Influence of internal features. Biosystems Eng. 100:266-280.

Fregonesi, J. A., C. B. Tucker, and D. M. Weary. 2007. Overstocking reduces lying time in dairy cows. J. Dairy Sci. 90:3349-3354.

Grasso, F., G. De Rosa, F. Napolitano, A. Di Francia, and A. Bordi. 2007. Entrance order and side preference of dairy cows in the milking parlour. Ital. J. Anim. Sci. 6:187-194.

Green, M. J., A. J. Bradley, G. F. Medley, and W. J. Browne. 2007. Cow, farm, and management factors during the dry period that determine the rate of clinical mastitis after calving. J. Dairy Sci. 90:3764-3776.

Green, M. J., A. J. Bradley, G. F. Medley, and W. J. Browne. 2008. Cow, farm, and herd management factors in the dry period associated with raised somatic cell counts in early lactation. J. Dairy Sci. 91:1403-1415.

Haley, D. B., J. Rushen, and A. M. de Passille. 2000. Behavioural indicators of cow comfort: Activity and resting behaviour of dairy cows in two types of housing. Can. J. Anim. Sci. 80:257-263.

Hansen, M. N. 1999. Optimal number of clusters per milker. J. Agric. Res. 72:341-346.

Hillerton, J. E., I. Ohnstad, J. R. Baines, and K. A. Leach. 2002. Performance differences and cow responses in new milking parlours. J. Dairy Res. 69:75-80.

Huzzey, J. M., T. J. DeVries, P. Valois, and M. A. G. von Keyserlingk. 2006. Stocking density and feed barrier design affect the feeding and social behavior of dairy cattle. J. Dairy Sci. 89:126-133.

Huzzey, J. M., P. Valois, T. J. DeVries, M. A. G. von Keyserlingk, and D. M. Weary. 2005. Effect of stocking density and fence line barrier on the behavior of dairy cattle. J. Anim. Sci. 83(Suppl. 1):392. (Abstr.)

Krawczel, P. D., C. T. Hill, H. M. Dann, and R. J. Grant. 2008. Effect of stocking density on indices of cow comfort. J. Dairy Sci. 91:1903-1907.

Maller, C. J., P. H. Hemsworth, K. T. Ng, E. J. Jongman, G. J. Coleman, and N. A. Arnold. 2005. The relationships between characteristics of milking sheds and the attitudes to dairy cows, working conditions, and quality of life of dairy farmers. Aust. J. Agric. Res. 56:363-372.

Mee, J. F. 2004. Managing the dairy cow at calving time. Vet. Clin. North Am. Food Anim. Pract. 20:521-546.

Mentink, R. L., and N. B. Cook. 2006. Feed bunk utilization in dairy cows housed in pens with either two or three rows of free stalls. J. Dairy Sci. 89:134-138.

Sandrucci, A., A. Tamburini, L. Bava, and M. Zucali. 2007. Factors affecting milk flow traits in dairy cows: Results of a field study. J. Dairy Sci. 90:1159-1167.

Sanftleben, P., K. Knierim, H. J. Herrmann, C. Mueller, and E. von Borell. 2007. Critical Control Points (CCP) in dairy housing and equipment. Zuchtungskunde 79:339-362. 
Smith, J. F., D. V. Armstrong, M. J. Gamroth, and J. G. Martin 1997. Planning the milking center in expanding dairies. J. Dairy Sci. 80:1866-1871.

Tucker, C. B., D. M. Weary, and D. Fraser. 2004. Free-stall dimensions: Effects on preference and stall usage. J. Dairy Sci. 87:1208 1216.

Val-Laillet, D., A. M. de Passille, J. Rushen, and M. A. G. von Keyserlingk. 2008. The concept of social dominance and the social distribution of feeding-related displacements between cows. Appl. Anim. Behav. Sci. 111:158-172.
Veissier, I., J. Capdeville, and E. Delval. 2004. Cubicle housing systems for cattle: Comfort of dairy cows depends on cubicle adjustment. J. Anim. Sci. 82:3321-3337.

Wagner, A., R. W. Palmer, J. Bewley, and D. B. Jackson-Smith. 2001. Producer satisfaction, efficiency, and investment cost factors of different milking systems. J. Dairy Sci. 84:1890-1898.

Wechsler, B. 2007. Normal behaviour as a basis for animal welfare assessment. Anim. Welf. 16(SI):107-110. 